\title{
Percepção de mulheres jovens sobre a sexualidade e a imagem corporal pós mastectomia
}

\section{Young women's perception of sexuality and body image post mastectomy}

\author{
Carine Gazola $^{1}$, Daniela Bredow ${ }^{1}$, Hedioneia Maria Foletto Pivetta ${ }^{2}$, \\ Melissa Medeiros Braz ${ }^{2}$
}

http://dx.doi.org/10.11606/issn.2238-6149.v28i1p93-99

\begin{abstract}
Gazola C, Bredow D, Pivetta HMF, Braz MM. Percepção de mulheres jovens sobre a sexualidade e a imagem corporal pós mastectomia. Rev Ter Ocup Univ São Paulo. 2017 jan.-abr.;28(1):93-9.

RESUMO: O objetivo desse estudo foi compreender a percepção sobre a imagem corporal e a sexualidade de mulheres jovens submetidas à mastectomia. Foi realizado um estudo transversal com uma abordagem qualitativa. Para a análise da sexualidade e da imagem corporal foi realizada uma entrevista semi-estruturada. Participaram do estudo quatro mulheres que tiveram diagnóstico de câncer de mama antes dos 35 anos de idade. Na análise das entrevistas, emergiram duas categorias: Percepção e significação da mama: da dor da perda até a satisfação e valorização da vida; Repercussões sobre a feminilidade e sexualidade: o enfrentamento da alteração da libido, das mudanças conjugais até a aceitação e o amadurecimento emocional. Concluiu-se com o estudo que a mastectomia interfere negativamente na imagem corporal e na sexualidade da mulher jovem, uma vez que a mama possui um simbolismo de feminilidade e saúde durante todas as etapas da vida da mulher. Também foram identificados pontos positivos, como a superação do câncer e a ressignificação da imagem corporal e da sexualidade, fazendo com que essas mulheres desenvolvam uma nova visão da sua vida, do seu corpo e das suas necessidades sexuais.
\end{abstract}

DESCRITORES: Sexualidade; Mastectomia; Imagem corporal/psicologia; Neoplasias da mama/cirurgia.
Gazola C, Bredow D, Pivetta HMF, Braz MM. Young women's perception of sexuality and body image post matectomy. Rev Ter Ocup Univ São Paulo. 2017 Jan.-Apr.;28(1):93-9.

ABSTRACT: The aim of this study was to understand the perception about body image and sexuality of young women submitted to mastectomy. A cross - sectional study was carried out with a qualitative approach. A semi-structured interview was performed for the analysis of sexuality and body image. Four women who had a diagnosis of breast cancer before the age of 35 participated in the study. In the analysis of the interviews, two categories emerged: Perception and signification of the breast: from pain of loss to satisfaction and appreciation of life; Repercussions on femininity and sexuality: coping with changing libido, from marital changes to acceptance and emotional maturation. It was concluded that mastectomy negatively interferes with the body image and sexuality of young women, since the breast has a symbolism of femininity and health and during all stages of the woman's life. Positive points have also been identified, such as overcoming cancer and re-signification of body image and sexuality, making these women develop a new vision of their life, body and sexual needs.

KEYWORDS: Sexuality; Mastectomy; Body image/ psychology; Breast neoplasms/surgery.

Trabalho de Conclusão do Curso de Fisioterapia da Universidade Federal de Santa Maria, RS, Brasil.

1. Acadêmica do Curso de Fisioterapia da Universidade Federal de Santa Maria (UFSM), Santa Maria, RS, Brasil. E-mail: carinegazola@ yahoo.com.br; danielabredow93@gmail.com

2. Professora Adjunta, Departamento de Fisioterapia e Reabilitação da Universidade Federal de Santa Maria (UFSM), Santa Maria, RS, Brasil.Email: melissabraz@hotmail.com; hedioneia@yahoo.com.br

Endereço para correspondência: Melissa M. Braz. Universidade Federal de Santa Maria, Centro de Ciências da Saúde, Departamento de Fisioterapia e Reabilitação. Av. Roraima, 1000 - Sala 4116, Prédio 26C. Cidade Universitária, Bairro Camobi, Santa Maria, RS, Brasil. CEP: 97105-100. E-mail: melissabraz@hotmail.com 


\section{INTRODUÇÃO}

o contexto mundial, o câncer da mama $(\mathrm{CM})$
é a segunda neoplasia maligna mais comum
na população ${ }^{1}$, sendo, entre as mulheres, o mais frequente câncer diagnosticado e a principal causa de morte por câncer, com $23 \%$ (1,38 milhões) do total de casos novos por ano ${ }^{2}$. No Brasil a estimativa de novos casos para 2016 é de $57.960^{3}$.

O carcinoma de mama é pouco comum em mulheres jovens, com menos de 35 anos de idade, constituindose em $5 \%$ a $7 \%$ dos casos em algumas séries, porém tem sido observado um aumento de sua incidência em faixas etárias mais jovens ${ }^{4,5}$. O CM em mulheres jovens ainda é mal compreendido e acredita-se que a doença apresenta-se biologicamente mais agressiva, com maior frequência de características histopatológicas adversas e piores resultados, o que contribui para um pior prognóstico quando comparada às mulheres mais velhas 6 .

Um dos métodos mais utilizados para o tratamento do $\mathrm{CM}$ é a mastectomia, uma cirurgia que visa à remoção de toda a mama ${ }^{7}$. A mastectomia é responsável por uma série de alterações vivenciadas pelas pacientes que a enfrentam, pois surge como um processo cirúrgico agressivo, acompanhado de consequências traumáticas para a vida e saúde da mulher ${ }^{8}$.

O CM, possivelmente, é a neoplasia mais temida pelas mulheres, uma vez que a sua ocorrência causa grande impacto psicológico, funcional e social, atuando negativamente nas questões relacionadas à autoimagem e à percepção da sexualidade .

Pesquisas mostram que mulheres jovens mastectomizadas são acometidas com mais problemas em relação à sua sexualidade, indicando que elas têm maior risco para estresse psicológico, disfunção sexual e maior dificuldade em se adaptar à nova imagem corporal ${ }^{10,11}$.

Mediante o exposto, o objetivo deste estudo foi compreender a percepção sobre a imagem corporal e a sexualidade de mulheres jovens que foram submetidas à mastectomia após câncer de mama.

\section{METODOLOGIA}

Foi realizado um estudo transversal com caráter qualitativo aprovado pelo Comitê de Ética em Pesquisa com Seres Humanos (CEP) institucional (número do parecer 1.180.351), conforme as normas estabelecidas da Resolução n.466/2012 do Conselho Nacional de Saúde.

As mulheres participantes da pesquisa foram provenientes da lista de espera dos serviços de mastologia e de fisioterapia de um hospital do interior do Rio Grande do Sul. A população foi composta por mulheres com diagnóstico de $\mathrm{CM}$ antes dos 35 anos de idade, que realizaram mastectomia.

Foram incluídas no estudo mulheres diagnosticadas com CM antes dos 35 anos de idade, que realizaram procedimento cirúrgico de mastectomia e mantinham vida sexual ativa. Os critérios de exclusão do estudo consistiam em diagnóstico de outros tipos de câncer, metástases ou condições clínicas que comprometessem a coleta das informações, gestação durante o período da coleta de dados e mulheres que desenvolveram CM durante a gestação.

As coletas de dados foram realizadas no Ambulatório de Fisioterapia do hospital em um horário definido pela voluntária, através do agendamento prévio com as pesquisadoras, sem tempo de duração estipulado. Após esclarecimentos do propósito do estudo a voluntária leu e assinou o Termo de Consentimento Livre e Esclarecido (TCLE).

A elaboração da entrevista semi-estruturada deuse através da análise dos objetivos da proposta de pesquisa que gerou um roteiro de tópicos formulados pelas autoras de modo que pudesse ser desenvolvido o mais naturalmente possível, em forma de diálogo. Os tópicos propostos no roteiro abrangeram a influência da mastectomia na imagem corporal e as possíveis repercussões dessas alterações na sexualidade. Foram utilizados tópicos abertos, que deram a flexibilidade de pensamento às entrevistadas, para que assim houvesse maior entendimento e resgate da realidade vivida pela mulher mastectomizada ${ }^{12}$. A entrevista semi-estruturada foi validada para esse estudo com mulheres mastectomizadas que não compuseram a amostra da pesquisa.

As entrevistas foram gravadas e a análise qualitativa dos dados foi realizada de acordo com Minayo ${ }^{13}$. Primeiramente procedeu-se a transcrição das entrevistas para posterior leitura em profundidade dos depoimentos. Em seguida procedeu-se a unitarização dos termos destacando as palavras-chaves que mais representaram a essência do objeto investigado. $\mathrm{Na}$ sequência foi realizada a união dos depoimentos semelhantes em significado para constituir categorias sendo, posteriormente, analisados os conteúdos expressos nos mesmos obtendo a interpretação do que pudesse refletir a imagem corporal e sexualidade destas mulheres ${ }^{13}$. Para a preservação do anonimato das participantes do estudo, utilizou-se da nomenclatura de pedras preciosas para representar cada uma das mulheres.

\section{RESULTADOS E DISCUSSÃO}

Participaram do estudo quatro mulheres que tiveram diagnóstico de câncer de mama antes dos 35 anos de idade. 
Quanto à escolaridade, as mulheres apresentaram ensino superior completo ou ensino médio completo. $\mathrm{O}$ estado civil característico das participantes foi a união estável. O tempo entre a data da entrevista e da mastectomia variou de 2 a 5 anos. Apenas uma das participantes não teve filhos até o momento.

Após a interpretação das entrevistas, os dados unitarizados foram agrupados em unidades de registro que geraram duas categorias: Percepção e significação da mama: da dor da perda até a satisfação e valorização da vida; Repercussões sobre a feminilidade e sexualidade: o enfrentamento da alteração da libido, das mudanças conjugais até a aceitação e o amadurecimento emocional.

\section{Percepção da significação da mama, desde a dor da perda até a satisfação e valorização da vida}

Essa categoria emergiu de elementos representativos das narrativas das mulheres que denotam as suas reações, desde o momento da descoberta da doença até a satisfação por ter vencido o $\mathrm{CM}$, a adaptação à nova realidade e/ ou valorização da vida e a redescoberta de si, o autoconhecimento e a ressignificação da vida. As narrativas das mulheres retratam os momentos de significação originários das fases vivenciadas no processo de enfrentamento da doença. Por meio dos depoimentos foi possível identificar o abalo emocional gerado pela perda da mama, mas também a superação dessa perda em detrimento da valorização da vida.

Os trechos seguintes demonstram os diversos sentimentos, como também a insegurança sobre o futuro no momento da descoberta do diagnóstico de $\mathrm{CM}$.

Antes tu vai se despedindo da mama, eu sabia que iria ficar sem ela (...), foi bem doloroso, eu chorei, tomei banho e chorei muito. Porque tu sabe que no dia seguinte será diferente. (Ametista)

Com certeza foi um cair num buraco, bem dificil. (Turquesa)

Eu não queria tirar a mama, eu não queria ficar sem mama. Todo mundo dizia: ah, bota silicone, mas eu não queria, eu queria os meus seios, eu queria ficar como eu era, normal! (Safira).

A confirmação do diagnóstico é descrito pelas mulheres como um momento de incerteza e de difícil aceitação para a mulher, uma vez que surgem dúvidas sobre como será a realidade após a cirurgia, bem como a dificuldade de aceitação da sua nova autoimagem corporal, sem a mama. O diagnóstico de $\mathrm{CM}$ carrega os tabus de uma doença chamada "maldita", possível causadora de desfiguração de partes do corpo e até do próprio atrativo sexual, e traz sofrimentos por seu tratamento ser prolongado ${ }^{14}$. Isso faz com que a mulher que recebe essa notícia entre em um momento decisivo em sua vida, porque a partir de então, vários aspectos de sua vida deverão ser reformulados ${ }^{15}$.

A mama é um símbolo de fertilidade e saúde e durante todas as etapas da vida da mulher, desde a infância, puberdade, até a vida adulta, é o órgão que está mais relacionado à feminilidade ${ }^{16}$, lidar com alterações corporais, principalmente porque são relacionadas à mama, é algo muito difícil para a mulher, independente da faixa etária em que se encontra ${ }^{17}$.

Apesar dos sentimentos que emanam da descoberta do câncer as mulheres buscam estratégias de superação para a perda da mama e passam a demonstrar satisfação pelo enfrentamento da doença. As falas fazem referência à vida que prevalece à perda da mama.

Quando eu acordei (...) e coloquei a mão eu senti que estava fundo, sem volume, sem nada, estava só o curativo e com a faixa enrolada em toda a volta do corpo (...) mais uma parte que eu passei, estou bem, estou aqui, estou viva. (Safira)

Eu me gosto e eu acho que eu descrevo como uma cicatriz da vitória. Porque muitas mulheres não chegam, não tem a oportunidade de chegar ao se olhar no espelho e ter uma cicatriz. (...) Tenho aquela vontade de falar para as pessoas sabe, de mostrar para as pessoas que tem vitória em tudo isso. (Turquesa)

O câncer de mama surge com um significado de ameaça à vida e à integridade física e emocional da mulher. Após o diagnóstico de CA de mama a mulher passa a vivenciar a expectativa de um futuro incerto com medo da morte e da mutilação ${ }^{18}$. Em seguida a mulher encontra-se no período pós-operatório que é marcado pela ambivalência, ou seja, há o alívio de ter sobrevivido à cirurgia e a esperança de estar curada ${ }^{19}$. Isto pode ser observado nos depoimentos coletados nesse estudo, assim como no estudo de Martins et al. ${ }^{20}$, que relata o anseio pela vida e medo da morte ficam evidentes.

Também compõem as narrativas das mulheres a maneira como elas se adaptaram gradualmente à nova realidade, e, mais do que isso, demonstram sentimentos de resignação pelo episódio da doença, o que as leva a atribuir novos valores à vida.

Foi sofrido, foi muito dificil, mas ao mesmo tempo eu já consigo, três anos depois, identificar que veio tudo isso para mim como pessoa, para melhorar. Então, eu 
Gazola C, et al. Percepção de mulheres jovens sobre a sexualidade. Rev Ter Ocup Univ São Paulo. 2017 jan./abr.;28(1):93-9.

já consegui significar isso de uma maneira positiva na minha vida. (Ametista)

Hoje acho que já não me preocupo mais, não fiz a reconstrução, não pretendo fazer e no verão já tentei me adaptar com roupas. Eu estou me sentindo bem assim. (Turquesa)

É comum as mulheres mastectomizadas passarem por um doloroso processo de adaptação ao "novo" corpo, à nova condição e às novas expectativas ${ }^{21}$. Muitas apresentam dificuldade em realizar escolhas, tais como; a roupa apropriada para vestir-se ou até mesmo o contato físico com outra pessoa ${ }^{22}$. A vida social dessas mulheres se modifica, no momento em que estas restringem o seu estilo de vida para realizarem o tratamento e suas consequências ${ }^{23}$. $\mathrm{O}$ enfrentamento do problema pode atenuar as situações estressantes, produzir esperança, mostrar alternativas que proporcionem conforto emocional e que ajudem no aprendizado de novas habilidades e comportamentos ${ }^{24}$.

O conteúdo escolhido para compor esse elemento frisa a redescoberta de si, o auto-conhecimento e a ressignificação da própria vida.

Amadurecimento, fé, tu não tem outra saída a não ser acreditar. (...) Acho que amor no sentido de se amar, amar viver, no sentido de não colocar a tua felicidade nas mãos dos outros sabe, um certo protagonismo, ser protagonista da tua vida das tuas decisões. (Ametista)

A vivência do câncer dificulta a criação de alternativas e frente a essa situação, mas que, de certo modo, surgem sentidos subjetivos que têm poder de reconfigurar sua própria existência e encontrar novas alternativas para o enfrentamento da doença, o que pressupõe protagonismo feminino perante a necessidade de reorganização de sua vida ${ }^{25}$. Após a cirurgia, percebe-se que surgem questões relativas à reelaboração da auto-estima e da imagem corporal. Assim, mulheres que passaram pela mastectomia, quando retornam às suas vidas cotidianas, tendem a reelaborar o processo vivido. Nesse sentido, a necessidade de cuidar-se é despertada quando há a descoberta e isso depende apenas de si mesma ${ }^{26}$. Então, quando questionadas sobre seus sonhos, perspectivas de futuro e reflexões frente às suas condições de vida, as respostas foram rápidas, objetivas e enriquecidas de esperança, fazendo valer, de forma positiva, suas experiências diante da doença ${ }^{20}$.

Essa categoria trouxe narrativas com elementos que representaram as reações das mulheres no momento da descoberta e diagnóstico de CM, nelas, os sentimentos foram retratados através da negação, aceitação e adaptação frente a essa dificuldade. Com o decorrer do tempo e do tratamento observa-se nas mulheres a aceitação do próprio corpo, a sensação de vitória e a atribuição de novos valores à vida.

Repercussões na feminilidade e na sexualidade: o enfrentamento da alteração da libido, das mudanças conjugais até a aceitação e o amadurecimento emocional

Para a composição dessa categoria foram elencados os seguintes elementos definidores: o reflexo do tratamento sobre a sexualidade da mulher, incompatibilidade sexual (separação conjugal) ou harmonização sexual (união conjugal), e a satisfação sexual após a auto-aceitação e o domínio do próprio corpo.

As narrativas demonstram o impacto das diferentes situações enfrentadas durante o tratamento do CM, como os efeitos ocasionados pela quimioterapia, a influência das alterações estéticas na autoimagem corporal e a repercussão sobre a libido, na medida em que as mulheres não se sentem à vontade para expor seu corpo ao parceiro, influências estas que variam durante as fases do tratamento.

Na época da quimioterapia (...) não tinha a menor condição
de ter desejo sexual. (Ametista)

Muda bastante no sentido de ficar totalmente à vontade. (...) tu te resguarda ou coloca uma roupa que vai tapar. Eu não consigo mais ficar totalmente nua na intimidade com o parceiro. (...), ele leva a mão e eu recuo, eu sinto que é coisa minha mesmo, porque falta ali né e a gente mulher. (Turquesa)

(...) quando eu tinha que fazer o curativo, eu até tinha um pouco de vergonha, não queria que ele olhasse. (Safira)

Não o desejo sexual diminuir, mas a disposição em se expor. (...), poderia até querer, mas não vou porque vou ter que tirar a roupa, daí não estou a fim de ser julgada, olhada, enfim. (Ametista).

A maioria dos estudos constata que há decréscimo do desejo e interesse sexual durante o tratamento para o $\mathrm{CM}$ e que isso ocorre, em maior escala, em mulheres submetidas à quimioterapia. Porém, este efeito adverso do tratamento tende a diminuir ao longo do tempo ${ }^{27}$. Neste contexto, a mama é vista como o objeto central de desejo e satisfação, e a doença compromete as possibilidades de simbolização do feminino na mulher. Quando ameaçada da perda deste órgão, a mulher sente que sua identidade feminina está sendo desconstruída, bem como a sua sensualidade ${ }^{28}$. As mulheres mastectomizadas 
Gazola C, et al. Percepção de mulheres jovens sobre a sexualidade. Rev Ter Ocup Univ São Paulo. 2017 jan./abr.;28(1):93-9.

apresentam depreciação em relação ao corpo, sendo que a maior preocupação em relação à sua imagem corporal está relacionada com o fato de sentirem o seu corpo incompleto. Além disso, algumas das mulheres acreditam que o corpo é fundamental na relação entre o homem e a mulher ${ }^{29}$. Diante disso, torna-se difícil enfrentar o retorno a vida sexual após mastectomia. A maioria das mulheres refere vergonha de mostrar-se nua na frente de seus parceiros, preferindo, então, manter relações sexuais com um sutiã ou camiseta ${ }^{30}$.

Observa-se que, apesar da aceitação e resignação após a descoberta da doença, as mulheres passam por momentos em que a vida sexual sofre interferências que vão desde a diminuição do desejo sexual, a vergonha diante do colo mutilado até a dúvida quanto às reações do parceiro.

Entretanto, alguns relatos são surpreendentes e demonstram as diferentes reações dos parceiros. Em tais situações o parceiro pareceu compreender o momento vivido, e esse entendimento possibilitou a consolidação da relação conjugal que transcende a problemática da doença. Nesses casos, se pode inferir que a ocorrência do difícil processo do tratamento, que é de longa duração, resultou em harmonização sexual e maior união conjugal.

Não mudou! Até a gente se uniu mais ainda com toda a história e nisso dele aceitar e tratar super bem, ter cuidado. (Safira)

Percebe-se que algumas mulheres têm dificuldade em se adaptar à essa nova fase da vida, então, o apoio das pessoas próximas é fundamental ${ }^{31}$. Desse modo a família é apontada como um dos elementos mais importantes na recuperação, porque proporciona ajuda e apoio ${ }^{32}$. Nesse contexto está inserido o parceiro, sendo que a proteção e a segurança por ele demonstradas proporcionam suporte para o enfrentamento dos problemas e para a relação interpessoal que possibilite compartilhar emoções, dúvidas e preocupações ${ }^{33}$. No entanto, os efeitos da mastectomia sobre a vida do casal dependem da relação conjugal, e da qualidade do relacionamento sexual e envolvimento emocional ${ }^{34}$ antes da intervenção cirúrgica.

Apesar de existirem companheiros que conseguem superar as situações impostas pela doença, também foram relatadas dificuldades dos parceiros em enfrentarem e serem capazes de apoiar a mulher. $\mathrm{O}$ parceiro pode sentir-se sexualmente insatisfeito, demonstrar insegurança, o que pode levar a não aceitação da situação ou ainda a atitudes de fuga, que podem ocasionar uma separação conjugal.

(...) ele não soube me ajudar naquilo que eu precisei, não me deu apoio da forma que eu gostaria que ele me desse. (...), eu disse: "olha eu estou seguindo esse rumo e você está indo para este e para a gente poder seguir junto, ou tu vem para o meu lado ou a gente não fica mais junto, porque eu não vou voltar, muita coisa mudou, eu sou outra pessoa e eu não vou voltar a ser quem eu era". (Jade)

O meu parceiro não gostou porque tirou o mamilo e ele tava associando à perda da sensibilidade durante a relação sexual, (...), porque poderia afetar meu prazer digamos, minha satisfação sexual. Eu não gostei disso, fiquei desapontada com essa reação que ele teve. (Jade)

Na época ele me cobrava muito, "tu não gosta mais de mim”, "tu não me deseja mais", "tu não quer mais ficar comigo", "a gente virou amigos". Porque eu não tinha vontade de ter relação sexual com ele, eu queria deitar e dormir e esquecer que eu tava vivendo, esquecer que eu existia, esquecer da minha vida. (Ametista)

Eu parei de menstruar, sentia calorões, acordava de noite tirando tudo, toda a roupa, aquela coisa de menopausa, sentia um calor absurdo. Eu estava careca, com um expansor de pele, sem um pelo no corpo inteiro, perdendo unha, "eu não quero fazer sexo, eu não quero, a última coisa que vou querer fazer agora é sexo" entendeu?! O meu parceiro, obviamente, eu não tiro o direito dele de querer ter uma relação normal, só que não era uma situação normal! Então assim, ele me cobrava muito. Muitas vezes eu cedia, outras eu não queria mais ceder, porque eu também estava em transformação, eu como pessoa! (Ametista)

As mulheres acometidas pelo CM apresentam comprometimento no exercício da sexualidade. Em consequência, após a retirada da mama ocorre também dor, fadiga, mal-estar após a quimioterapia, perda do desejo sexual, estresse emocional ${ }^{35}$, então torna-se fundamental a boa comunicação entre o casal para que a vida sexual e íntima possa ser reorganizada após o adoecimento, sem deixar de levar em consideração as necessidades e sentimentos de cada $u^{36}$. Desta forma é de extrema importância para a mulher a dedicação do companheiro. Isso porque, com a doença, a mulher sente a necessidade de aceitação, afeição, compreensão e carinho por parte do parceiro. De acordo com a compreensão delas, na falta desses sentimentos, o relacionamento sexual fica totalmente desestimulante ${ }^{29}$. É importante ressaltar como os cônjuges ficam abalados, frente ao impacto da doença e da mastectomia. Muitas vezes, o companheiro se vê fora do contexto, pois fica desprovido de cuidados psicológicos e emocionais para enfrentar essa fase, o que pode acarretar isolamento pessoal ou até mesmo separação conjugal ${ }^{37}$. 
Gazola C, et al. Percepção de mulheres jovens sobre a sexualidade. Rev Ter Ocup Univ São Paulo. 2017 jan./abr.;28(1):93-9.

O terceiro elemento definidor demonstra o amadurecimento emocional e reconhecimento de si, o que levou ao autodomínio uma vez que se observa a superação das fases anteriores possibilitando às mulheres irem além e agregar significado a tudo que veio decorrente da doença e seu tratamento. Nesta fase, os ideais de vida de cada mulher encontram-se transformados e estabelecidos. A satisfação sexual não vem somente do desejo em si, mas sim, da nova concepção de beleza, ou seja, da própria imagem a qual foi gradativamente ressignificada e valorizada. A mulher acaba por confiar em si mesma e reconhecer no seu próprio corpo as sensações e desejos, como também aprende a valorizar distintamente a vida, o que pode conduzir a sua satisfação sexual.

Hoje eu faço sexo quando eu estou com vontade de fazer sexo, eu não cedo à vontade de namorado que está querendo ou a obrigação que a mulher tem em cumprir uma função sexual. (...) Eu me fidelizei muito mais com a minha sexualidade depois do CA do que antes, em função de todo sofrimento, eu digo "tem que ser bom pra mim também, tem que ser algo que eu quero também”. Mas no sentido de achar que a minha libido tá maior ou menor, não sinto muita diferença. (Ametista)

Depois passa, vai passando, tu vai se acostumando e tu já resolve que não vai dar tanta explicação toda vez que quiser se relacionar com uma pessoa nova (...) A conversa se tornou muito mais breve, chega de tanta explicação. (Ametista)

Melhorou (a vida sexual). Melhorou porque eu me sinto mais segura. Então assim, hoje eu me vejo muito melhor do que eu era, sabe, a gente se enxerga de outra forma (...) a gente se redescobre como mulher, eu acho que até a força, a coragem e a gente percebe que a beleza está em qualquer lugar (Jade)

O significado e a importância que a mulher mastectomizada atribui à modificação de uma parte do corpo

Conflitos de interesse: Não houve conflitos de interesse.

\section{REFERÊNCIAS}

1. Instituto Nacional de Câncer José Alencar Gomes da Silva. Mama. Estimativa 2016: incidência de câncer no Brasil. Rio de Janeiro; 2016 [citado 19 maio 2016]. Disponível em: http:// www2.inca.gov.br/wps/wcm/connect/tiposdecancer/site/home/ mama. podem interferir no seu comportamento sexual. A sexualidade é um fator muito importante, uma vez que possibilita a mulher sentir-se segura e desejada, e dessa forma poder melhorar sua autoestima $^{38}$. É natural que a mulher sinta medo e angústia ao se falar de relação sexual, pois ela sofreu uma mudança abrupta em seu corpo e leva tempo até que se acostume e incorpore essa mudança ${ }^{39}$. Considerando que as circunstâncias vivenciadas, de certo modo impõe a ressignificação do papel da sexualidade, neste caso, o diagnóstico de câncer pode inferir sobre a qualidade da experiência sexual pós mastectomia, uma vez que, possivelmente a satisfação sexual está relacionada com a maneira como a sexualidade é ressignificada na vida da mulher ${ }^{37}$.

Diante do exposto, pode-se inferir que o diagnóstico do $\mathrm{CM}$, assim como o tratamento necessários para a doença causam impactos em diferentes situações da vida da mulher. Percebe-se nas narrativas que há interferência direta na autoimagem e, consequentemente na sexualidade. Isso pressupõe pensar que a sexualidade consiste em importante elemento a ser considerado pelos profissionais que acompanham as mulheres em tratamento para o câncer de mama, pois o modo como a mulher se percebe e implica na maneira como esta se relaciona com seu parceiro. Para além disso, a relação harmônica entre o casal é um fator importante para que a mulher se sinta segura para enfrentar as dificuldades nas diferentes fases do tratamento.

\section{CONSIDERAÇÕES FINAIS}

Nesse estudo pudemos concluir que a retirada da mama interferiu na imagem corporal e na sexualidade da mulher jovem que realizou a mastectomia, uma vez que a mama possui uma grande significação para a mulher, portanto a mesma sofre a dor da perda, mas pode superar de forma positiva suas limitações e assim passar a valorizar ainda mais a vida. Também observamos que a mulher jovem passa pelo processo de ressignificação da sua imagem corporal e consequentemente da sua sexualidade, iniciando uma nova visão de seu corpo e das suas necessidades sexuais.

2. Hayes DF. Clinical practice. Follow-up of patients with early breast cancer. N Engl J Med. 2007;356(24):2505-13. doi: http:// dx.doi.org/10.1056/NEJMcp067260.

3. Alves PC, Silva APS, Santos MCL, Fernandes AFC. Conhecimento e expectativas de mulheres no pré-operatório da 
Gazola C, et al. Percepção de mulheres jovens sobre a sexualidade. Rev Ter Ocup Univ São Paulo. 2017 jan./abr.;28(1):93-9.

mastectomia. Rev Esc Enferm USP. 2010;44(4):989-95. doi: http://dx.doi.org/10.1590/S0080-62342010000400019.

4. Panjari M, Bell RJ, Davis SR. Sexual function after breast cancer. J Sex Med. 2011;8(1):294-302. doi: http://dx.doi. $\operatorname{org} / 10.1111 / \mathrm{j} .1743-6109.2010 .02034 . x$.

5. Moura FMJP, Silva MG, Oliveira SC, Moura LJSP. Os sentimentos das mulheres pós-mastectomizadas. Esc Anna Nery. 2010;14(3):477-84. doi: http://dx.doi.org/10.1590/ S1414-81452010000300007.

6. Rzeznik C, Dall'agnol CM. (Re)descobrindo a vida apesar do câncer. Rev Gaúcha Enferm (Porto Alegre). 2000;21(n. esp):84-100. Disponível em: http://seer.ufrgs.br/index.php/ RevistaGauchadeEnfermagem/article/view/4329/2287.

7. Duarte TP, Andrade NA. Enfrentando a mastectomia: análise do relato de mulheres mastectomizadas sobre questões ligadas à sexualidade. Estud Psicol. 2003;8(1):155-63. doi: http://dx.doi.org/10.1590/S1413-294X2003000100017.

8. Silva RM, Rodrigues DP, Gurgel AH, Farias LM. Auto-exame das mamas em mulheres jovens e a relação com o autocuidado. Rev Rene (Fortaleza). 2000;1(1):9-13. doi: http://dx.doi. org/10.15253/rev\%20rene.v1i1.5901.

9. Ramos WSR, Sousa FS, Santos TR, Junior WRS, França ISX, Figueiredo GCAL. Sentimentos vivenciados por mulheres acometidas por câncer de mama. J Health Sci Inst. 2012;30(3):241-8.

10. Camargo TC, Souza IEO. Atenção à mulher mastectomizada: discutindo os aspectos ônticos e a dimensão ontológica da atuação da enfermeira do Hospital do Câncer III. Rev LatinoAm Enfermagem. 2003;11(5):614-21. doi: http://dx.doi. org/10.1590/S0104-11692003000500008.

11. Martins MMB, Farias MDBS, Silva IS. Sentimentos pós mastectomia em mulheres atendidas em uma associação de apoio às pessoas com câncer. Rev Gest Saúde (Brasília). 2016;7(2):596-607. Disponível em: http://gestaoesaude.unb.br/ index.php/gestaoesaude/article/view/1509/pdf.

12. BossoiS E, Gimene FGO, Alves KR, Estevão MB, Paulino I. Sentimentos da mulher mastectomizada. Universo Enfermagem. 2013;2(1):5-19 [citado 8 jun. 2016]. Disponível em: http:// novavenecia.multivix.edu.br/wp-content/uploads/2013/05/ universo_enf_03.pdf Acessado em 08 de junho de 2016.

13. Aureliano WA. “... e Deus criou a mulher”: reconstruindo o corpo feminino na experiência do câncer de mama. Rev Estud Fem. 2009;17(1):49-70. doi: http://dx.doi.org/10.1590/S0104026X2009000100004.
14. Gonçalves SROS, Arrais FMA, Fernandes AFC. As implicações da mastectomia no cotidiano de um grupo de mulheres. Rev Rene (Fortaleza). 2012;8(2):9-17. doi: http://dx.doi.org/10.15253/ rev\%20rene.v8i2.5280

15. Ferreira MLSM, Mamede MV. Representação do corpo na relação consigo mesma após mastectomia. Rev Latinoam Enfermagem. 2003;11(3):299-304. doi: http://dx.doi. org/10.1590/S0104-11692003000300006.

16. Avis NE, Crawford S, Manuel J. Psychosocial problems among younger women with breast cancer. Psycho-Oncology. 2004;13(5):295-308. doi: 10.1002/pon.744.

17. Vieira CP, Lopes MHBM, Shimo AKK. Sentimentos e experiências na vida das mulheres com câncer de mama. Rev Esc Enferm USP. 2007;41(2):311-6. doi: http://dx.doi. org/10.1590/S0080-62342007000200020.

18. Costa AMN, Pereira ER, Vasconcelos TB, Farias MSQ, Praça LR, Bastos VPD. Mulheres e a mastectomia: revisão literária. RAS Rev Atenção Saúde. 2015;13(44):58-63. doi: 10.13037/ rbcs.vol13n44.2713.

19. Deitos TFH, Gaspary JFP. Efeitos biopsicossociais e psiconeuroimunológicos do câncer sobre o paciente e familiares. Rev Bras Cancerol. 1997;43(2):117-26. Disponível em: http:// www.inca.gov.br/rbc/n_43/v02/english/article3.html.

20. Fernandes AFC, Mamede MV. Câncer de mama: mulheres que sobreviveram. Fortaleza: Editora UFC; 2003.

21. Ferreira SMA, Panobianco MS, Gozzo TO, Almeida AM. A sexualidade da mulher com câncer de mama: análise da produção científica de enfermagem. Texto Contexto Enferm. 2013;22(3):835-42. doi: http://dx.doi.org/10.1590/S010407072013000300033 .

22. Cesnik VM, Santos MA. Mastectomia e sexualidade: uma revisão integrativa. Psicol Reflex Crít. 2012;25(2):339-49. doi: http://dx.doi.org/10.1590/S0102-79722012000200016.

23. Ibiapina ARS, Mais JM, Costa e Silva LD, Fernandes MA, Costa Filho AAI, Fernandes RO. Aspectos psicoemocionais de mulheres pós-mastectomizadas participantes de um grupo de apoio de um hospital geral. R Interd. 2015;8(3):135-42. Disponível em: http://revistainterdisciplinar.uninovafapi.edu.br/ index.php/revinter/article/view/775/pdf_243.

24. Vasconcelos PM, Neves JB. Importância do apoio familiar à mulher submetida à cirurgia para tratamento da neoplasia mamária. Rev Enferm Integrada. 2010;3(1):422-32. Disponível em: https:/www.unilestemg.br/enfermagemintegrada/artigo/ v3/05-importancia-apoio-familiar-mulher.pdf. 